\title{
Теплофизические свойства наножидкостей и критерии подобия
}

\author{
(C) В.Я. Рудяк ${ }^{1}$, А.В. Минаков ${ }^{1,2, \uparrow}$, М.И. Пряжников ${ }^{1,2}$ \\ ${ }^{1}$ Новосибирский государственный архитектурно-строительный \\ университет \\ ${ }^{2}$ Сибирский фредеральный университет, Красноярск \\ "E-mail: Aminakov@sfu-kras.ru
}

Поступило в Редакцию 27 июня 2016 г.

Проведено экспериментальное исследование зависимости числа Прандтля для наножидкости от концентрации, размера и материала наночастиц. Исследуемые наножидкости были приготовлены на основе дистиллированной воды и наночастиц оксидов кремния, алюминия, титана и циркония. Объемная концентрация наночастиц изменялась в диапазоне от 1 до $8 \%$. Диаметр наночастиц варьировался от 10 до $150 \mathrm{~nm}$. Установлено, что с ростом концентрации наночастиц число Прандтля для наножидкостей возрастает. При этом показано, что значение числа Прандтля существенно зависит от размера частиц. С увеличением размера частиц число Прандтля для наножидкостей уменьшается.

Наножидкости, т. е. дисперсные жидкости с наночастицами, активно изучаются уже более двадцати лет. Это связано, во-первых, с многочисленными уже существующими или планируемыми приложениями, а во-вторых, с их нестандартными свойствами. Теплофизические свойства наножидкостей, в частности их вязкость и теплопроводность, не описываются классическими теориями (см., например, [1-3]). И коэффициент вязкости, и коэффициент теплопроводности наножидкостей зависят не только от концентрации частиц, но и от их размера. Сегодня уже ясно, что вязкость наножидкостей существенно превышает вязкость крупнодисперсных жидкостей, а в работах [4,5] методом молекулярной динамики и экспериментально установлено, что она зависит также от материала частиц. Данные измерений коэффициента теплопроводности все еще остаются достаточно противоречивыми. Наряду с констатацией его роста с увеличением размера частиц [1] существуют и прямо противоположные мнения (см., например, [6,7]). Поэтому изучение зависимости коэффициента теплопроводности наножидкости от размера 
Зависимость коэффициентов вязкости и теплопроводности наножидкостей от объемной концентрации наночастиц

\begin{tabular}{c|c|c|c|c|c|c|c|c|c|c|c}
\hline \multicolumn{2}{c|}{$\mathrm{Al}_{2} \mathrm{O}_{3}(150 \mathrm{~nm})$} & \multicolumn{2}{c|}{$\mathrm{TiO}_{2}(150 \mathrm{~nm})$} & \multicolumn{2}{c|}{$\mathrm{ZrO}_{2}(44 \mathrm{~nm})$} & \multicolumn{3}{|c}{$\mathrm{ZrO}_{2}(105 \mathrm{~nm})$} \\
\hline$\varphi$ & $\lambda$ & $\mu$ & $\varphi$ & $\lambda$ & $\mu$ & $\varphi$ & $\lambda$ & $\mu$ & $\varphi$ & $\lambda$ & $\mu$ \\
\hline 0.01 & 1.06 & 1.06 & 0.01 & 1.05 & 1.09 & 0.02 & 1.08 & 1.17 & 0.02 & 1.09 & 1.14 \\
0.02 & 1.13 & 1.13 & 0.02 & 1.10 & 1.18 & 0.04 & 1.14 & 1.32 & 0.04 & 1.17 & 1.24 \\
0.04 & 1.18 & 1.38 & 0.04 & 1.15 & 1.57 & 0.06 & 1.17 & 1.59 & 0.06 & 1.22 & 1.52 \\
0.06 & 1.24 & 1.60 & 0.06 & 1.21 & 1.91 & 0.08 & 1.19 & 2.16 & 0.08 & 1.28 & 2.11
\end{tabular}

частиц все еще актуально и является первой задачей данной работы. На практике во всех приложениях наножидкостей и в лабораторных исследованиях имеют место их течения. При описании течений наножидкостей, как и обычных флюидов, используют известные критерии подобия: числа Рейнольдса, Прандтля, Нуссельта и т. д. Однако сложная зависимость коэффициентов вязкости и теплопроводности от концентрации наночастиц, их размера и материала делает нередко получаемые выводы неадекватными. Одним и тем же значениям тех или иных критериев подобия могут соответствовать просто различные наножидкости. Изучение зависимости указанных критериев подобия от теплофизических характеристик наножидкостей - вторая задача этой заметки.

Коэффициент вязкости наножидкостей измерялся с помощью ротационного вискозиметра Brookfield DV2T с адаптером для малой вязкости ULA(0) (см. также [5]). Погрешность измерения коэффициентов вязкости была не выше $2 \%$. Для измерения коэффициента теплопроводности применялся метод нагреваемой проволочки, используемая установка и ее тестирование детально описаны в работе [8]. Итоговая относительная погрешность измерения коэффициента теплопроводности составляла около $2 \%$. Анализ погрешности показал, что итоговая относительная погрешность определения числа Прандтля составляет $3 \%$.

Исследовались наножидкости на основе дистиллированной воды и наночастиц. Для их приготовления применялся стандартный двухшаговый процесс. После добавления в воду необходимого количества нанопорошка наножидкость сначала механически перемешивалась, а затем обрабатывалась в ультразвуковой ванне „Сапфир“. Наночастицы были приобретены у компании „Плазмотерм“(Москва). Изучена вяз-

Письма в ЖТФ, 2016, том 42, вып. 24 
кость и теплопроводность почти пяти десятков наножидкостей. Во всех случаях частицы имели сферическую (или близкую к ней) форму. Измерение распределения наночастиц по размерам уже непосредственно в жидкости было проведено с помощью прибора CPS Disk Centrifuge DC24000. Объемная концентрация частиц варьировалась от 1 до 8\%, а их размеры - от 10 до $150 \mathrm{~nm}$.

Данные измерений, проведенных при температуре $25^{\circ} \mathrm{C}$, представлены в таблице и на рис. 1. При рассмотренных концентрациях $\varphi$ зависимость коэффициента вязкости от нее во всех случаях может быть описана формулой

$$
\mu=\mu_{0}\left(1+a_{1} \varphi+a_{2} \varphi^{2}\right),
$$

где $\mu_{0}-$ коэффициент теплопроводности базовой жидкости (воды), a $a_{i}$ - некоторые константы. Полученные данные свидетельствуют о том, что, во-первых, вязкость наножидкости существенно выше вязкости воды и не описывается классическими теориями (Эйнштейна, Бэтчелора и т.п.). Так, например, теория Эйнштейна, применимая при концентрации $1 \%$, дает во всех случаях одинаковое значение, равное 1.025 (см. таблицу). Во-вторых, коэффициент вязкости наножидкостей действительно зависит от размера и материала частиц, причем он тем больше, чем меньше этот размер. Наконец, коэффициент вязкости у наножидкостей тем больше, чем выше плотность материала входящих в нее частиц.

Коэффициент теплопроводности так же, как и коэффициент вязкости, зависит от размера наночастиц, он растет с увеличением размера частиц. Его зависимость от концентрации частиц снова можно аппроксимировать простой формулой, которая, однако, качественно отличается от (1):

$$
\lambda=\lambda_{0}\left(1+b_{1} \varphi-b_{2} \varphi^{2}\right) .
$$

Здесь $\lambda_{0}-$ коэффициент теплопроводности базовой жидкости (воды), a $b_{i}$ - некоторые константы. Зависимость (2) показывает, что, начиная с некоторых концентраций частиц, рост коэффициента теплопроводности замедляется, а затем выходит на некоторое предельное значение. Это соответствует и другим известным экспериментальным данным $[9,10]$ и молекулярно-динамическому моделированию [11].

Разберемся теперь с особенностями использования критериев подобия при описании течений наножидкостей. Вначале рассмотрим число Рейнольдса $\operatorname{Re}=(\rho U L) / \mu(\rho, U-$ соответственно плотность и характерная скорость жидкости, а $L-$ характерный масштаб течения,

Письма в ЖТФ, 2016, том 42, вып. 24 


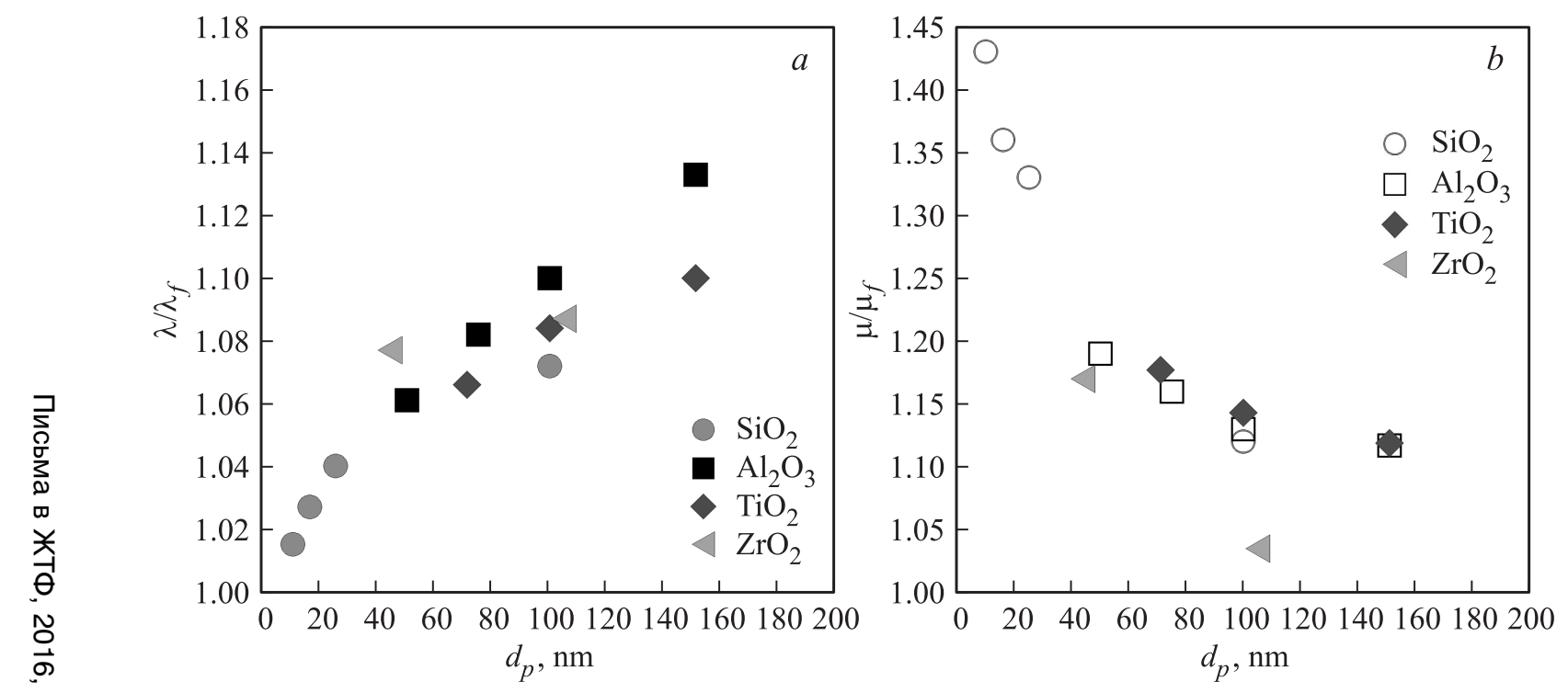

Рис. 1. Зависимость относительного коэффициента теплопроводности наножидкостей $(a)$ и относительного коэффициента вязкости наножидкостей $(b)$ от размера частиц, $\varphi=2 \%$. 
диаметр канала, расстояние между пластинами и т.п.) Плотность является линейной функцией концентрации наночастиц, а коэффициент вязкости - квадратичной (см. (1)). Таким образом, число Рейнольдса также является квадратичной функцией концентрации частиц. Далее, коэффициенты $a_{i}$ в формуле (1) являются функциями размера частиц и их материала. Поэтому часто приводящиеся в работах по моделированию течений наножидкостей зависимости тех или иных параметров от числа Рейнольдса без конкретизации характеристик наножидкости просто невозможно физически разумно интерпретировать. Гораздо сложнее обстоит дело с числом Прандтля $\operatorname{Pr}=\left(C_{p} \mu\right) / \lambda$, где $C_{p}$ - теплоемкость жидкости. Экспериментально показано [12], что теплоемкость наножидкости хорошо описывается выражением $C_{p}=\left[(1-\varphi) \rho_{f} C_{p f}+\varphi \rho_{p} C_{p p}\right] \rho^{-1}$, где $\rho_{f}$ и $C_{p f}-$ плотность и теплоемкость несущей жидкости, $\rho_{p}$ и $C_{p p}$ - плотность и теплоемкость материала наночастицы, $\rho-$ плотность наножидкости: $\rho=(1-\varphi) \rho_{f}+\varphi \rho_{p}$. Сопоставление соотношений (1) и (2) показывает, что при рассматриваемых небольших (примерно до 10\%) концентрациях частиц число Прандтля также является квадратичной функцией $\varphi$ концентрации частиц $\left(\operatorname{Pr}_{w}\right.$ - число Прандтля воды)

$$
\operatorname{Pr}=\operatorname{Pr}_{w}\left\lfloor 1+k_{1}(d, m) \varphi+k_{2}(d, m) \varphi^{2}\right\rfloor .
$$

Пример зависимости (3) показан на рис. 2,a для наножидкости с частицами $\mathrm{ZrO}_{2}$, с ростом концентрации частиц число Прандтля наножидкости значительно возрастает. Однако коэффициенты $k_{i}$ в (3) не универсальны, они зависят от размера частиц $d$ и их материала $m$. Первая зависимость иллюстрируется рис. $2, a$, вторая - рис. $2, b$, где приведены данные наножидкости на основе воды с частицами $\mathrm{Al}_{2} \mathrm{O}_{3}$ и $\mathrm{TiO}_{2}$ в зависимости от их концентрации (см. таблицу), причем размеры частиц в обоих случаях были одинаковы. Стоит отметить, что коэффициенты $k_{i}$ в (3) в общем случае могут быть знакопеременными. Поэтому при некоторых значениях параметров наножидкости число Прандтля наножидкости может оказаться ниже числа Прандтля базовой жидкости. На рис. 2, $b$ это наблюдается в наножидкости при малых концентрациях оксида алюминия. Наблюдаемое повышение числа Прандтля с ростом концентрации частиц связано с тем, что с ее увеличением коэффициент вязкости наножидкости возрастает значительно быстрее, чем коэффициент теплопроводности. Действительно, в приведенных данных измерений максимальное превышение коэффициента теплопроводности фиксируется у наножидкости с частицами $\mathrm{ZrO}_{2}$ (выше 28\%), в то

Письма в ЖТФ, 2016, том 42, вып. 24 

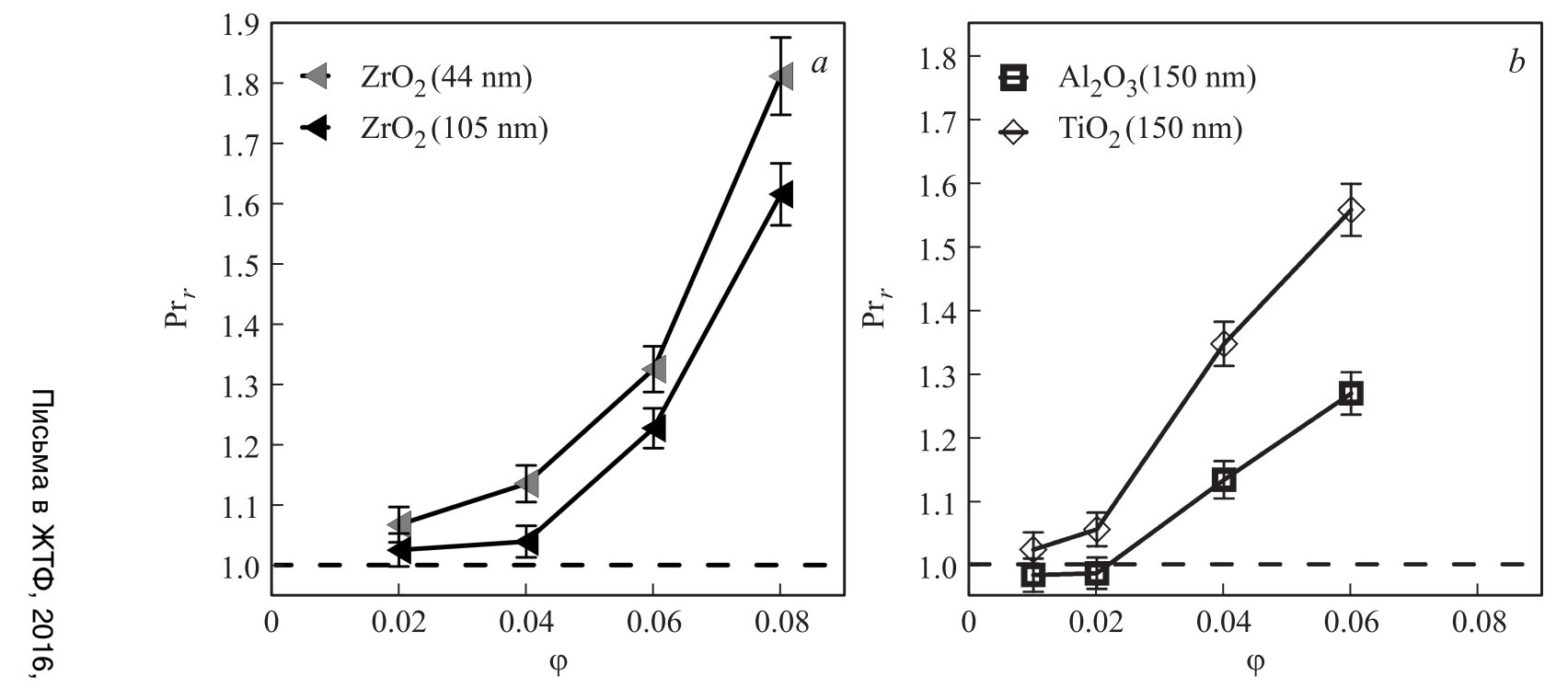

Рис. 2. Зависимость относительного числа Прандтля $\operatorname{Pr}_{r}=\operatorname{Pr} / \operatorname{Pr}_{w}$ наножидкости на основе воды от концентрации частиц $\mathrm{ZrO}_{2}(a)$ и от концентрации частиц $\mathrm{Al}_{2} \mathrm{O}_{3}$ и $\mathrm{TiO}_{2}(b)$. 


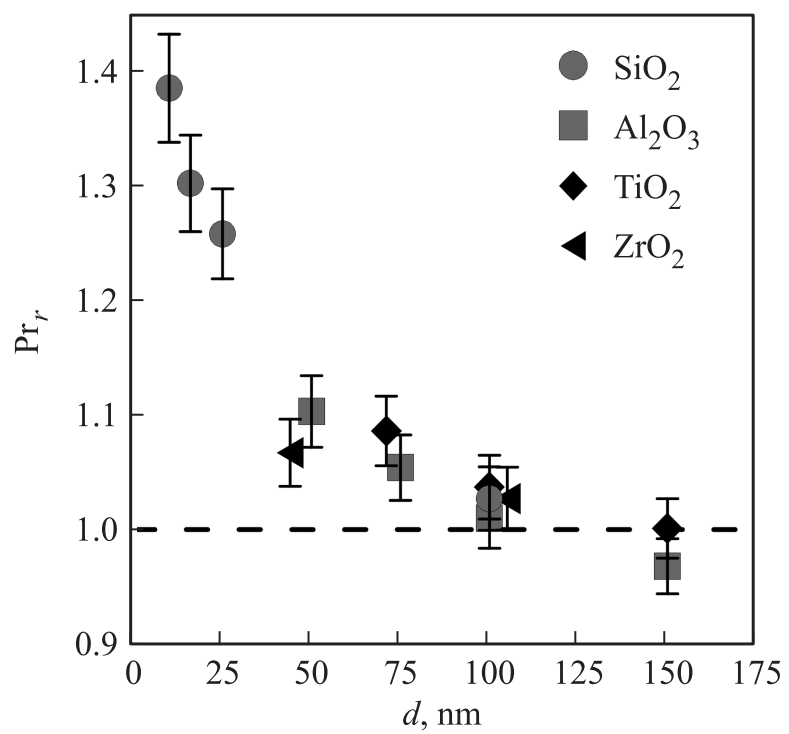

Рис. 3. Зависимость относительного числа Прандтля наножидкости $\operatorname{Pr}_{r}$ от размера наночастиц, $\varphi=2 \%$.

же время коэффициент вязкости с увеличением концентрации частиц возрастает более чем вдвое. Тем не менее возможно и обратное. Особенно значительный рост коэффициента теплопроводности наножидкостей наблюдается при использовании металлических частиц (даже при очень низких их концентрациях, см., например, обзор [13]). Коэффициент вязкости и теплоемкость такой наножидкости меняются очень слабо и будет наблюдаться снижение числа Прандтля по сравнению с соответствующим значением для базовой жидкости.

Зависимость коэффициентов вязкости и теплопроводности наножидкостей от размера наночастиц противоположная: вязкость с уменьшением размера частиц растет, а теплопроводность падает. Поэтому максимальные значения числа Прандтля должны наблюдаться у наножидкостей с малыми частицами. По мере их роста число Прандтля будет снижаться. Это подтверждает рис. 3, построенный по данным рис. 1. Как видно, при концентрации частиц $2 \%$ зависимость числа Прандтля наножидкостей от индивидуальных свойств материалов частиц -

Письма в ЖТФ, 2016, том 42, вып. 24 
порядка погрешности измерений. Зависимость от материала становится заметной только при более высоких концентрациях (рис. 2, $b$ ).

В заключение отметим, что еще более сложная ситуация реализуется при использовании числа Нуссельта $\mathrm{Nu}=\alpha L / \lambda$, где $\alpha-$ коэффициент теплоотдачи. При небольших концентрациях наночастиц коэффициент теплоотдачи растет пропорционально концентрации частиц, но одновременно он в общем случае зависит от их размера, а также вязкости наножидкости $[14,15]$.

Таким образом, в данной работе впервые было показано, что с ростом концентрации наночастиц число Прандтля для наножидкостей возрастает. При этом установлено, что значение числа Прандтля для наножидкостей уменьшается с увеличением размера частиц.

Работа выполнена при частичной финансовой поддержке Российского научного фонда (соглашение № 14-19-00312).

\section{Список литературы}

[1] Timofeeva E.V. et al. // Nanotechnology. 2010. V. 21. N 21. P. 215703.

[2] Рудяк В.Я. // Вестник НГУ. Физика. 2015. Т. 10. № 1. С. 5-22.

[3] Kumar P.M. et al. // Engineering J. 2015. V. 19. Iss. 1. P. 67-83.

[4] Rudyak V.Yz., Krasnolutskii S.L. // Phys. Lett. A. 2014. V. 378. P. 1845-1849.

[5] Рудяк В.Я., Минаков А.В., Сметанина М.С., Пряжников М.И. // Доклады Академии наук. 2016. Т. 467. № 3. С. 289-292.

[6] Chon C.H., Kihm K.D., Lee S.P., Choi S.U.S. // Appl. Phys. Lett. 2005. V. 87. P. 153107.

[7] Mintsa H.A., Roy G., Nguyen C.T., Doucet D. // Int. J. Thermal Sci. 2009. V. 48. P. 363-371.

[8] Минаков А.В. и др. // Инженерно-физический журнал. 2015. Т. 88. № 1. C. $148-160$.

[9] Zhu H.T., Zhang C.Y., Tang Y.M., Wang J.X. // J. Phys. Chem. C. 2007. V. 111. P. 1646-1650.

[10] Keblinski P., Prasher R., Eapen J. // J. Nanopartarticles Res. 2008. V. 10. P. 1089-1097.

[11] Рудяк В.Я., Белкин А.А. // Наносистемы: Физика, Химия, Математика. 2010. T. 1. № 1. C. 156-177.

[12] Zhou S.Q., Ni R. // Appl. Phys. Lett. 2008. V. 92. P. 93-123.

[13] Wang X.-Q., Mujumdar A.S. // Int. J. Thermal Sci. 2007. V. 46. P. 1-19.

[14] Гузей Д.В., Минаков А.В., Рудяк В.Я., Дектерев А.А. // Письма в ЖТФ. 2014. T. 40. В. 5. C. $34-42$.

[15] Гузей Д.В., Минаков А.В., Рудяк В.Я. // Изв. РАН. МЖГ. 2016. № 2. С. 65-75.

Письма в ЖТФ, 2016, том 42, вып. 24 